\title{
The Role of Timely Actionable Student Feedback in Improving Instruction and Student Learning in Engineering Courses
}

\section{Dr. Petros Sideris, Zachry Department of Civil and Environmental Engineering, Texas A\&M University}

Dr. Sideris is an Assistant Professor at the Zachry Department of Civil and Environment Engineering at Texas A\&M University, since 2017. Prior to joining Texas A\&M, Dr. Sideris was an Assistant Professor at the University of Colorado at Boulder, where he also served as the Director of the Structures and Materials Testing Laboratory. He received his Master's (2008) and Ph.D. (2012) in Civil Engineering from the University at Buffalo - SUNY. He also holds a diploma in Civil Engineering (2005) from the National Technical University of Athens, Greece. Prior to joining the University of Colorado at Boulder, Dr. Sideris was appointed as Post-doctoral Research Fellow and Adjunct Lecturer at the University at Buffalo - SUNY (September 2012 - May 2013). Dr. Sideris has taught courses in statics, mechanics of materials, structural dynamics, applied mathematics and numerical methods, reinforced concrete design, and experimental methods. His research primarily focuses on the areas of Resilient and Sustainable Structures and Computational Mechanics for Damage, Softening and Structural Collapse. Dr. Sideris is an Associate Member of the American Society of Civil Engineers (ASCE) and serves in the ASCE/SEI Seismic Effects Committee and the ASCE/EMI Computational Mechanics Committee. He is also a Young Affiliate Member of the Transportation Research Board (TRB) of the National Academies, and serves as a member of the TRB's AFF-50 Standing Committee on Seismic Design and Performance of Bridges. Dr. Sideris is also an ExCEEd fellow since the summer of 2017.

\section{Dr. Maria Koliou, Zachry Department of Civil and Environmental Engineering, Texas A\&M University}

Dr. Koliou is an Assistant Professor at the Zachry Department of Civil and Environment Engineering at Texas A\&M University. She joined the department after having been a Post-doctoral Fellow at the NISTfunded Center of Excellence for Risk-based Community Resilience Planning at Colorado State University. She received her Diploma (2008) in Civil Engineering from the University of Patras, Greece, while she holds Master's (2010) and PhD (2014) degrees from the University at Buffalo - SUNY. Her research interests span the fields of structural dynamics, earthquake engineering, and multi-hazard performance-based design for system functionality and community resilience. Through these areas, her research focuses on developing novel sustainable structural designs and systems against natural and man-made hazards and formulating fundamental mathematical frameworks to assess system functionality and community resilience. Dr. Koliou is an Associate Member of the American Society of Civil Engineers (ASCE) and serves in technical committees including the Structural Engineering Institute (SEI) Design of Wood Structures Committee, the SEI Disaster Resilience of Structures, Infrastructure \& Communities Committee and the Engineering Mechanics Institute (EMI) Objective Resilience Committee. Dr. Koliou also served as the co-chair of the Earthquake Engineering Research Institute's (EERI) Younger Members committee during 2017-2019. She received the 2018 Structural Engineering Institute's Young Professional Scholarship. Dr. Koliou has taught courses in Engineering Mechanics: Dynamics, Structural Steel Design, Engineering Risk Analysis and Concrete Design. She is also an ExCEEd fellow since summer 2019 which further attests to her devotions to teaching and education. 


\title{
The Role of Timely Actionable Student Feedback in Improving Instruction and Student Learning in Engineering Courses
}

\begin{abstract}
Traditional course instruction has students on the receiving end, giving them limited opportunity to contribute to their learning environment, and improve their learning experiences. The most common, and often only, form of course-level student feedback typically used in most universities is an end-of-semester survey, which has no influence on the current course, and provides a slow path to improvement. This study presents a student-centered assessment model that provides timely actionable feedback allowing optimization of course instruction during the semester with the objective of maximizing student learning and the overall student satisfaction. The proposed model uses a simple structured approach that incorporates questions requiring numerical scores and open-ended questions to solicit student feedback.
\end{abstract}

This model includes four surveys administered over the semester. The first survey is given on the first week of classes to familiarize the instructor with the background and career goals of each student and their course expectations. Based on the findings of this survey, the instructor can adjust or clarify aspects of the learning objectives, help students strategize their studying based on their individual background, and plan, early on, a "fine tuning" of the course schedule to add needed or remove obsolete material. The second and third surveys are anonymous and give the students the opportunity to assess various aspects of the course and their learning experiences. Each survey is separated into three sections. The Course section focuses on assessing the course structure, including the course organization, teaching tools, instructor's lecture notes, textbooks, and homework. The Instructor section focuses on assessing the instructor's overall support of the course, including their teaching skills, responsiveness to questions, learning environment, and academic concern. The TA section includes an overall rating for the teaching assistant (TA). At the end of each section, a "Comments/Suggestions" box is included, where the students are encouraged to write their comments. These surveys are administered typically at $1 / 3$ (Week 5) and $2 / 3$ (Week 10) of the semester.

Based on the findings of each survey, the instructor makes a brief presentation during class, where the most frequent comments/issues are discussed along with actions to address them. The third survey further serves as a measure of the efficiency of the adopted actions from the second survey. The fourth survey is administered by the university typically during Week 14 of the semester and serves as a final assessment provided by an independent entity. This assessment model has been applied by the authors in two universities for the undergraduate courses of Statics, Engineering Mechanics: Dynamics, Structural Concrete Design and Computer Applications in Engineering and Construction, and the graduate courses of Advanced Mechanics of Materials, Structural Dynamics and Engineering Risk Analysis. The findings of this study show that timely actionable feedback is essential in improving student learning and satisfaction within the semester, and helps increasing engagement and excitement for a course, because the students realize that their opinion matters and can shape the structure of a course to their benefit. Statistical analyses of the surveys are presented and the sample surveys are provided as an assessment tool to potentially be adopted by other educators in engineering courses. 


\section{Introduction}

Traditional course instruction has students on the receiving end, giving them limited opportunity to contribute to their learning environment, and improve their learning experiences. In traditional course instruction, the instructor decides all aspects of the course to its very fine details, which he/she implements during the semester. Student feedback, the value of which has been identified from several studies [1-4], is limited within this process, most commonly taking the form of an end-of-semester survey, which is often mandated by State laws and, practically, has no influence on the learning experience of the students currently attending the course. Considering that, in most universities, the same course is given once a year and not always by the same instructor, improvements to the course structure and delivery as well as the learning environment are extremely slow; in the order of several years. The inefficiency of this approach is particularly consequential to the students, who are not given the opportunity to communicate their concerns in a timely manner, and, as a result, are exposed to learning environments that fail to engage them into the learning process, significantly hindering their learning of the course material [1-7]. The inefficiency of this approach is also consequential to junior faculty, who are required to improve their course instruction over short periods of time, usually 4 to 6 years, often with limited mentorship, usually via in-class evaluations conducted once a year by senior colleagues, and more recently, through additional university-level workshops.

\section{Scope}

The objective of this paper is to present a student-centered assessment model that provides timely actionable feedback allowing optimization of course instruction during the semester with the goal of maximizing student learning and the overall student satisfaction. The proposed model incorporates a simple structured approach that include questions requiring numerical scores and open-ended questions to solicit student feedback, mechanisms to assess, address and implement that feedback, and methods to validate the success of the implemented improvements.

The proposed model has been implemented in two universities (University of Colorado Boulder and Texas A\&M University) and has been utilized by two faculty, i.e. the two authors. Implementation of this course model resulted in an increase of the students' rating within the semester and has led to long-term improvements in the instruction and overall organization of those courses.

Unlike conventional formative models $[8,9]$ that focus on quantifying student learning through muddiest point papers or quizzes (and other methods $[8,9]$ ) and provide feedback to the students, this assessment model focuses on the student satisfaction for the entire course structure and delivery as well as the perceived learning of the material by the students based on feedback solicited by the students. By focusing on the student satisfaction and perceived learning of the material, the proposed model is complementary to, and should be used together with, summative assessment tools (e.g. HW assignments, quizzes, midterm exams, final exam), which explicitly focus on quantifying actual student learning in an absolute sense. This complementarity also rests on the fact that the performance of students in HW assignments and midterm/final exams is clearly associated with their overall satisfaction about the course structure and delivery $[10,11]$. 


\section{Description of the Proposed Assessment Model}

This model includes four online ( 3 via Google Forms and 1 via the University online survey system) surveys administered over the semester. The first survey -termed Student Info

Questionnaire - is given on the first week of classes and is intended to familiarize the instructor with the background and career goals of each student as well as their learning expectations from this course. Prior to administering this survey, the instructor should clarify the learning objectives and the entire structure of the course. This survey should not be administered prior to a complete presentation of the course syllabus. After this survey has been administered and the instructor has reviewed the student responses, he/she can adjust or clarify aspects of the learning objectives in class, and plan, early on, a "fine tuning" of the course schedule to add needed or remove obsolete material based on strengths and weaknesses on the students' technical background. It is often the case that students have expectations that do not align well with the learning objectives of a course, or may not have acquired sufficient technical competence in certain prior courses. Furthermore, the instructor can help individual students, upon their request, to strategize their studying based on their individual background and fill in such gaps.

A sample of a recently administered Student Info Questionnaire is shown in Figure 1. Although different instructors can select a different list of questions, some questions that are highly recommended are: (i) "list of prior relevant courses", not just the prerequisites, because they help the instructor identify gaps in the knowledge of fundamentals, (ii) the description of "expectations" for the course, and (iii) "anything else you would like [the instructor] to know", which provides a formal, yet discrete, venue for students to communicate potential difficulties and concerns. A set of other questions, such as those on hobbies and prior work experience, allow the instructor to get to know the students better and help establishing interpersonal rapport with them early on during the semester. Establishing interpersonal rapport often helps maintaining a good learning environment [12]. 


Student Info
Questionnaire
Please complete the survey so that thave the opportunity to learn more about you and
ensure a productive and useful educational envirionment.
lam looking forward to having you in this course!
- Requited
Name.
Your answer
Your State
O Texas
To other state

Expected Graduation Date

$\begin{array}{lccc} & \text { May } & \text { August } & \text { December } \\ 2020 & \square & \square & \square \\ 2021 & \square & \square & \square \\ 2022 & \square & \square & \square\end{array}$

\section{Class Rank *}

O Freshman

O sophomore

Junior

O serior

Graduate

Majorlntended major -

O structural Engineering

Geotechnical Engineering

Construction Engineering 8 Management

Transportation Engineering

Materials Engineering

O Environmental Engineering

Water Resources

$\mathrm{O}$ cosstal Engineering

$O$ General

List all major past mechanics and structural analysis courses and institution

Your answer
What are your expectations from this course?

Your answer

1. What are your plans following graduation? 2. Are you planning to pursue graduate studies? 3. Your long-term career goals?

Your answer

Have you ever had any work experience related to Civil Engineering? Please describe.

Your answer

Are you currently having a job? If so, how many hours do you devote to it each week?

Your answer

What would be your preferred activities in your free time?

Your answer

Is there anything else you would like me to know?

Your answer

\section{Figure 1. Example of Student Info Questionnaire}


The second and third online (via Google Forms) survey - termed $1^{\text {st }}$ and $2^{\text {nd }}$ Course Evaluation Survey - is anonymous and give the students the opportunity to assess various aspects of the course and their learning experiences. Each course evaluation survey is separated into three sections: the course section, the instructor section and the teaching assistant (TA) section. The Course section focuses on assessing the course structure, including the course organization, teaching tools, instructor's lecture notes, textbooks, and homework, the latter of which may appear as a separate subsection. The Instructor section focuses on assessing the instructor's overall support of the course, including their teaching skills, responsiveness to questions, learning environment, and academic concern. The TA section includes an overall rating for the TA, while more questions could be added based on the TA's involvement in the course. At the end of each section, a "Comments/Suggestions" box is included, where the students are encouraged to provide comments and suggestions about improving the course. Furthermore, the Course and the Instructor sections are completed with an "overall" course and instructor ratings, which represent the overall positive or negative perception of the students. These course evaluation surveys are administered typically at 1/3 (Week 5) and 2/3 (Week 10) of the semester. Prior to administering these surveys, it is important that the instructor briefly discusses their objectives during the class and emphasizes the fact that these surveys give voice to the students' concerns allowing for improvements in a timely manner and that the student input matters to the instructor. The authors usually administer these surveys, just days before midterm exams, thus, giving the students the opportunity to evaluate the class at the same time/period, when the instructor will evaluate their own learning. The authors' intention with this timing is to create a sense of fairness amongst the students, because both the instructor and the students are evaluated and evaluate, and rally them in supporting this entire evaluation model - yet, further research is needed to explore how giving the survey at other times may affect the students sense of fairness about the course delivery. After processing of the student responses, the instructor should present the findings in the next class, identifying the comments/concerns/issues mentioned by most students, and put forward actions that he/she will be taking to address them within the current semester.

While the $1^{\text {st }}$ course evaluation survey $\left(2^{\text {nd }}\right.$ survey of the model) primarily intends to identify concerns, i.e. areas for improvement, the $2^{\text {nd }}$ course evaluation survey ( $3^{\text {rd }}$ survey of the model) has a two-fold goal, namely, (i) assessing the efficiency of the adopted actions determined based on the findings of the $1^{\text {st }}$ course evaluation survey, and (ii) identifying new areas of improvement.

A sample of a recently administered Course Evaluation Survey is shown Figure 2. The survey includes more than 20 questions, evenly balanced between the Course and Instructor sections. The course section includes questions that assess course structure, class organization and preparation, course intellectual challenge, HW quality and grading fairness, overall learning, effectiveness of electronic media to support learning, and the usefulness of posted notes, and overall rating of the course. The instructor section includes questions that assess their presentation and explanation skills, their enthusiasm about the material, their effectiveness in encouraging interest for the material, their responsiveness to student questions, the overall class learning environment, their availability for assistance, and their concern about the students learning the material. Both sections end with a question on assessing the overall rating of the course and the instructor, respectively, as well as a "Comments/Suggestions" box for open ended 
recommendations. These questions (together with the TA evaluation section) provide a holistic review of all major aspects of a course, allowing the instructor to obtain broad and detailed student feedback to support future changes in the course delivery.

The rating scale used in the questions of the course evaluation surveys is selected to match the scale of the rating system of each university. Thus, course evaluation surveys administered in University A use a 6-point scale (A to F), whereas, course evaluation surveys administered in University B use a 5-point scale (A to E). "University A" refers to the Department of Civil, Environmental and Architectural Engineering at the University of Colorado Boulder, while "University B" refers to the Zachry Department of Civil and Environmental Engineering at Texas A\&M University. Also, for the discussions to follow, "Instructor 1" refers to the first author and "Instructor 2" refers to the second author. 


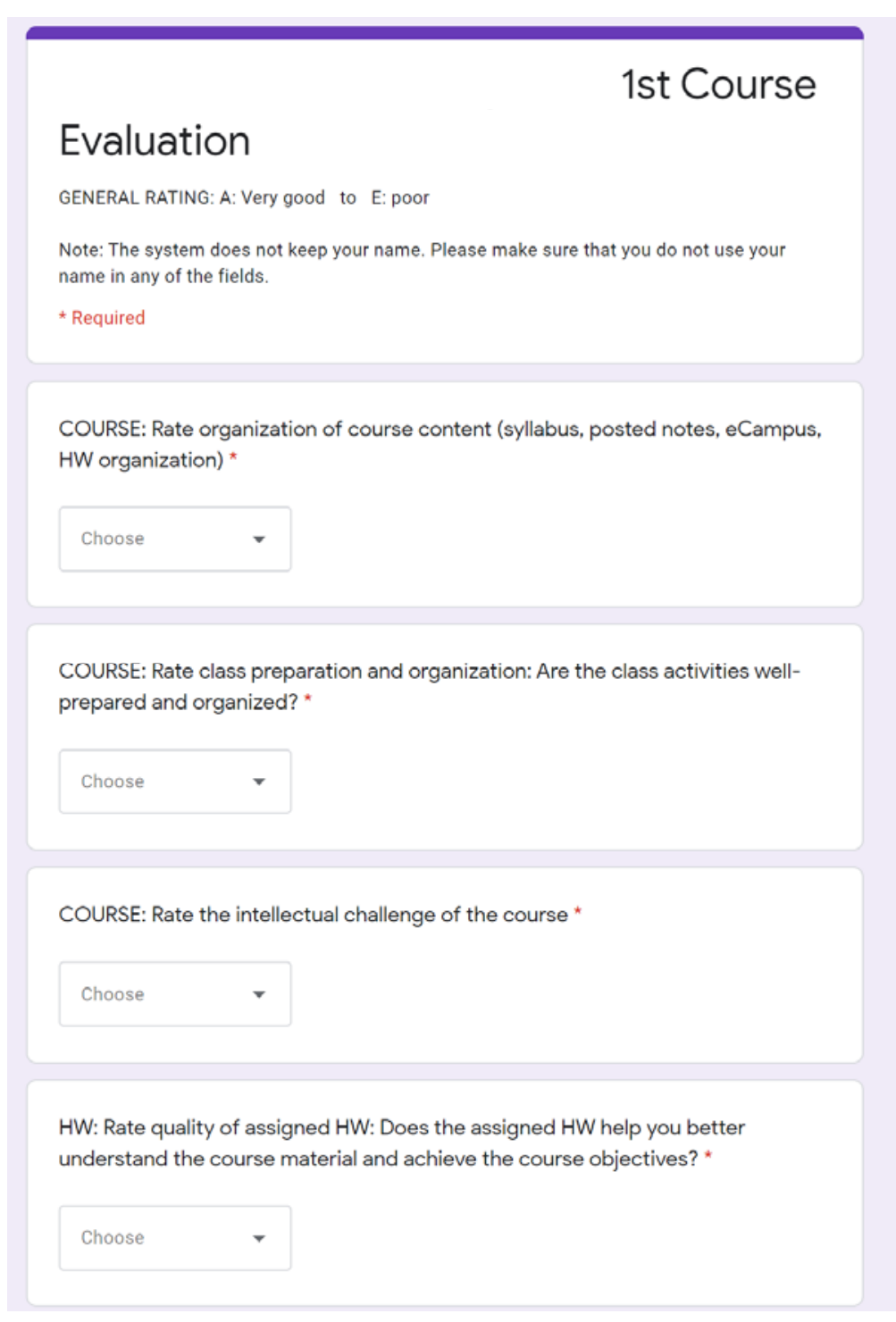

$\mathrm{HW}$ : Rate fairness in HW grading: Is the HW graded fairly and in accordance with the HW rules?

Choose $\quad-$

COURSE: Time you spend for the course (including classes) in hours/week *

Choose $\quad-$

COURSE: What percentage of the class have you attended? *

$$
\text { Choose }
$$

COURSE: What percentage of the office hours have you attended? *

Choose $\quad-$

COURSE: Rate how much you have learnt in this course so far *

Choose $\quad-$

COURSE: Rate effectiveness of electronic media (e.g., tablet, projector) to support student learning *

Choose


COURSE: Rate usefulness of posted notes *

Choose +

COURSE: Overall rating of the course *

Choose $\quad-$

COURSE: Comments/Suggestions on the course: 1. What do you like the most? 2.What do you like the least? 3. Other comments/suggestions? *

Your answer

INSTRUCTOR: Rate instructor's presentation and explanation skills: The instructor clearly explains the material so that I can understand it. *

Choose

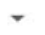

\section{INSTRUCTOR: Rate instructor's enthusiasm about the class *}

Choose

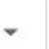

INSTRUCTOR: Rate instructor's effectiveness in encouraging interest *

$$
\text { Choose }
$$

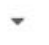

INSTRUCTOR: Rate instructor's responsiveness: The instructor is open to my questions, and effectively answers them. *

Choose $\quad$

INSTRUCTOR: Rate class learning environment: The instructor maintains a good learning environment for me. *

$$
\text { Choose }
$$

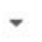

INSTRUCTOR: Rate instructor's availability for assistance: The instructor willingly makes time to help other students and me *

Choose $\quad-$

INSTRUCTOR: Rate instructor's academic concern: The instructor seems to care that I learn this material. *

Choose

INSTRUCTOR: Overall rating for the instructor *

$$
\text { Choose }
$$

INSTRUCTOR: Comments/Suggestions for the instructor *

Your answer 


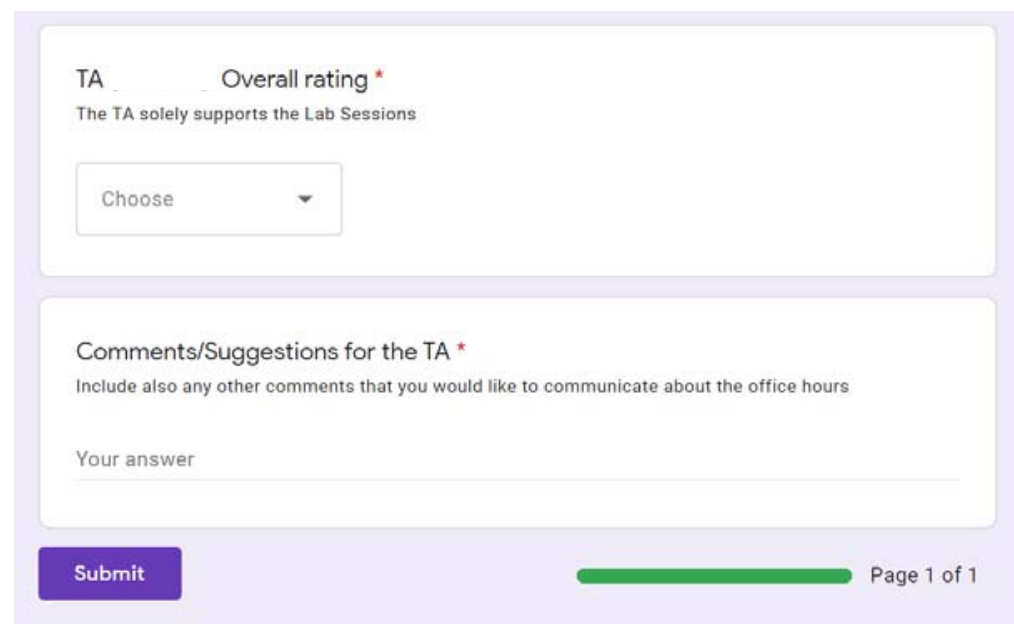

Figure 2. Example of Course Evaluation Survey 
The fourth survey - termed $3^{\text {rd }}$ Course Evaluation Survey - is also anonymous and is administered by the university typically during the last week of classes. This evaluation serves as a final assessment provided by an independent entity. Unfortunately, in most universities, the faculty cannot include their own questions and as a result a comparison of the first two surveys with the final survey is not always possible. However, the student feedback from this final survey (together with the feedback from the previous two course evaluation surveys) can be used to guide refinements in the design of the course, when it is delivered again by the instructor in the future.

\section{Implementation of the Proposed Assessment Model}

Implementation of the proposed assessment model is easy and straightforward, and requires only minimal time from the instructor. Indeed, it requires some time from the instructor to prepare the very first online student information questionnaire $\left(1^{\text {st }}\right.$ survey of the model $)$ and the very first online course evaluation survey ( $2^{\text {nd }}$ and $3^{\text {rd }}$ survey of the model). However, once those surveys are prepared once (e.g., in Google Forms), they can be used for several courses and over several years. Also, modifications to these forms to include more/less questions or modify existing questions are easy and can be performed rapidly.

Administering the survey does not require much time from the instructor. The authors, for example, usually administer these surveys by email or course announcement within the course website and give the students 2-3 days to respond.

Processing of the student responses is also straightforward and quick, because Google Forms (and other online platforms) automatically present summaries of the student responses. Thus, calculation of average values and standard deviations of the student ratings requires only minor post-processing by the instructor. Slightly more time demanding is the review of the course and instructor "Comments/Suggestions", which requires grouping of similar comments and quantification of their frequency, i.e. how many students have expressed the same concern. Following this processing, the instructor needs to identify major concerns, which should be addressed. In the authors' experience, concerns that are shared by more than $10-20 \%$ of the students of a course should be addressed by the instructor. The extent to which these comments are addressed depends on their frequency (and merit, based on the instructor's judgement). For example, concerns that are shared by more than $50 \%$ of the class could require major changes or re-structuring of the course (or part of it), whereas concerns shared by only $10-20 \%$ of the class could require only minor adjustments and should be implemented only if those are to the benefit of the majority. This is determined through a discussion of the course evaluation results with the students, preferably in the next class right after the due date of the course evaluation survey. At that time, the instructor should take 10 minutes to present the findings of the survey, the most major comments, questions with the lowest ratings, and actions that will be taken to address the identified concerns. Based on the authors' experience, processing of the student responses does not take more than 1-2 hours.

A challenge that could be faced in implementing this course assessment model is a low response rate by the students to the surveys. The authors have addressed this issue by setting target response rates, in the range of $90 \%$ or $95 \%$, and associating them with a bonus to the upcoming 
midterm exams or the final student scores. In addition to achieving very high response rates, this strategy also instils a sense of responsibility to the students towards their peers and the class, because lack of responsiveness of few students could strip the bonus from the entire class.

Examples of common student concerns that can be (or have been) identified by these surveys include the general structure of the course (particularly for courses including labs and other components different from traditional instruction), the structure of the lectures (e.g., number of in-class examples, pace of the material presentation, relation of theory to real world problems and applications), the structure of the solution of in-class examples, the HW assignment length and format requirements, the relevance/closeness/correlation of the HW assignments to the lecture material and in-class examples, fairness in HW grading, the class environment, requirements of prior knowledge of the fundamentals, and the availability for office hours from the instructor and the TA.

Except for changes relating to the above student concerns, other notable major changes/upgrades that the authors implemented in their course organization over the years as a result of these assessment models include: (i) the modification of a laboratory component from the course on numerical methods and computer programming, which changed the attitude of the students towards computer programming, from "despising it" (quoted from a student response) to a "passion", (ii) the formulation of HW assignment preparation guidelines that address issues such as presentation, neatness, and structure, through several cycles of student feedback, and (iii) the structure of the posted notes to include "pre-lecture notes", i.e. a set of notes for the entire chapter, but without the solutions to the presented examples, to help the students prepare prior to classes, "problems/examples-only notes", i.e. a set of notes including only the problem questions and oversized figures to use in their solutions, and final "lecture notes" updated in accordance with the material presented in class, including problem solutions.

\section{Results and Discussion}

The proposed assessment model has been implemented by two faculty ("Instructor 1" and "Instructor 2") in two universities ("University A" and "University B") for both undergraduate and graduate courses over a time period of five years. The undergraduate courses include those of Statics, Engineering Mechanics: Dynamics, Structural Concrete Design and Computer Applications in Engineering and Construction. The graduate courses include Structural Dynamics, Advanced Mechanics of Materials, and Engineering Risk Analysis. Instructor 1 utilized the proposed assessment model to its full extent (Tables 1 through 6), whereas Instructor 2 (Tables 7 and 8) utilized the same model with a shorter version of the course evaluation questionnaires ( $2^{\text {nd }}$ and $3^{\text {rd }}$ survey). All data are presented in the tables below in the form of comparisons between course evaluation surveys, including mean values for all administered questions, percentage increases to quantify the achieved improvements, and $p$-values to provide a preliminary quantification of the statistical significance of the observed improvements. A twosample double-tailed t-test with unequal variance and unequal sampled sizes was used to quantify the $p$-values, which represent the probability of obtaining results at least as extreme as the results actually observed by these comparisons, assuming that the null hypothesis is correct. Smaller $p$-values indicate a higher statistical significance, because they imply that the null hypothesis cannot explain the observed differences in the mean between the two samples. In this study, statistical significance is assumed to be referring to a significance level of $5 \%$. It is 
clarified that, although a more accurate statistical analysis that would account for proper probability distributions and sample sizes is possible, the analysis presented here is considered sufficient to identify trends within the context of this study.

According to these tables, the proposed assessment model clearly improves the quality of course instruction and learning environment during the semester and results in higher student satisfaction, particularly as this latter is reflected in the overall rating of the course and instructor (Q7/Q8 and Q16 in Tables 1 through 6, and several questions in Tables 7 and 8). Comparisons between the mean ratings from the $1^{\text {st }}$ and $2^{\text {nd }}$ course evaluation $\left(2^{\text {nd }}\right.$ and $3^{\text {rd }}$ survey of the model) show that these improvements are larger when the reference student ratings (i.e. the ratings of the first course evaluation) are below $80-85 \%$, i.e. when there is a $15-20 \%$ room for improvement. In this case, the improvement in the overall satisfaction for the course and the instructor can exceed 15\%, as shown by Q7 and Q16 in Table 1, Table 2 and Table 3, Q10 and Q18 in Table 4, Q8 and Q16 in Table 5, and Q9 in Table 7 and Table 8. These improvements, as is the case with all improvements exceeding $10 \%$, are statistically significant $(p<0.05)$. This overall satisfaction is clearly tied to the student learning (or the confidence of the students in their understanding of the course material), which usually reaches or exceeds the improvements of the overall course and instructor rating (and with a statistical significance, $p<0.05$ ), as shown by Q5 in Table 1, Table 2 and Table 3, Q8 in Table 4, and Q6 in Table 5. This is because students are more engaging and enjoy the course, when they feel they learn the material and can solve problems in HW assignments and exams. It is also observed that the achieved improvements are larger for large size classes ( $>100$ student), as shown by Q7 and Q16 in Table 2 , as opposed to smaller size classes ( $<50$ students), as shown in Table 1, because the logistics and management of larger classes are more demanding and it is more likely that minor details of the course structure and delivery have consequences for more students, which, in turn, result in lower reference student ratings, leaving more room for improvement.

Furthermore, it is observed that the achieved improvements are larger (and show statistical significance) for courses taught for the first time (or only 1-2 times) by an instructor, which could naturally result in low reference student ratings (i.e. below $80-85 \%$ in the first course evaluation $-2^{\text {nd }}$ Survey of the model), for which there is a larger room for improvement.

When the reference student ratings (i.e., first course evaluation $-2^{\text {nd }}$ Survey of the model) exceed $90-95 \%$, the proposed assessment model is not always capable of guaranteeing increases in the overall student satisfaction, because the room for improvement is small, as is the case for Statics - Spring 2015 (Table 1), Advanced Mechanics of Materials - Fall 2019 (Table 6), Engineering Mechanics: Dynamics - Spring 2019 (Table 7) and Engineering Risk Analysis- Fall 2018 (Table 8). This is because when a course structure and delivery has been well tuned for the class supermajority, any effort to address concerns of few students could dissatisfy other students. However, even in such cases, the reductions in student satisfaction are up to $3 \%-4 \%$ (or less), and are usually statistically insignificant ( $p>>0.05)$, particularly when the overall student satisfaction remains above $90-95 \%$.

From the tables below, it is also evident that in the first few years of applying this model, the authors faced the major challenge of occasionally low response rates to the surveys, which is also a challenge that most universities, including Universities A and B, have been facing. The authors 
have addressed this challenge by setting target response rates, in the range of $90 \%$ or $95 \%$, and associating them with a small bonus to the upcoming midterm exams or the final exam. This approach has indeed been successful in often achieving 100\% participation (e.g. Table 4, Table 6 and Table 7). An alternative approach that the authors also used was to encourage students during and after class to submit their response to those surveys, emphasizing the importance of their voice being heard. This approach, despite proving efficient in increasing the student response rate (e.g. Table 1, Table 3 and Table 8), did not always achieve consistently high response rates. Overall, despite the low response rates at the early years of implementation of this evaluation model, the aforementioned major findings hold true and have been confirmed by recent implementations of this model for which consistently higher response rates have been achieved.

It is worth noting that the proposed assessment model has also resulted in overall improvements in student ratings from semester to semester, as shown in Tables 1, 2, 3, 4 and 7. However, such a trend is not always the case (e.g., Table 5), because courses are fine-tuned differently from semester to semester, and also evolve over time (beyond typical fine-tuning), revising their material and their delivery methods. For example, in one semester all HW submission can be in hardcopy vs. online in the next semester, which creates mixed feelings amongst students who are now required to scan their hand-written solutions or type them in a word editor. The proposed assessment model is designed to solicit timely student feedback and allowing optimal incorporation of such changes within the semester, but, by extension, it can guide refinements from semester to semester. In other words, the authors implemented in later semesters policies and strategies that they developed in previous semesters. 
Table 1. Instructor 1 - University A - Undergraduate Course of Statics (CVEN 2121) - Smaller size classes (Max. Rating: 6)

\begin{tabular}{|c|c|c|c|c|c|c|c|c|c|}
\hline & \multirow{2}{*}{\multicolumn{4}{|c|}{ Statics - Spring 2014}} & \multirow{2}{*}{\multicolumn{4}{|c|}{ Statics - Spring 2015}} \\
\hline & & & & & & & & & \\
\hline & & Evaluation 1 & $\begin{array}{c}\text { Evalu } \\
\text { ation } \\
2\end{array}$ & \multirow{3}{*}{ 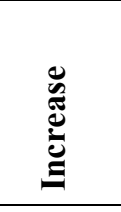 } & \multirow{3}{*}{ 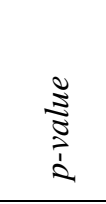 } & $\begin{array}{l}\text { Evaluatio } \\
\text { n } 1\end{array}$ & $\begin{array}{l}\text { Evaluati } \\
\text { on } 2\end{array}$ & \multirow{3}{*}{ 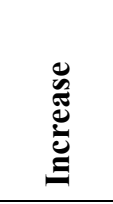 } & \multirow{3}{*}{ 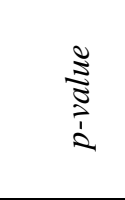 } \\
\hline & No. of Students enrolled & \multicolumn{2}{|l|}{45} & & & \multicolumn{2}{|c|}{52} & & \\
\hline & Response Rate & $67 \%$ & $53 \%$ & & & $38 \%$ & $62 \%$ & & \\
\hline Q1 & $\begin{array}{l}\text { COURSE: Rate organization of course content } \\
\text { (syllabus, textbook, notes, D2L) }\end{array}$ & 4.63 & 4.92 & $6.1 \%$ & 0.248 & 5.3 & 5.53 & $4.4 \%$ & 0.438 \\
\hline Q2 & $\begin{array}{l}\text { COURSE: Rate use of class time. Is the class time } \\
\text { efficiently used to promote student learning? }\end{array}$ & 4.43 & 4.46 & $0.6 \%$ & 0.930 & 4.95 & 5.13 & $3.5 \%$ & 0.542 \\
\hline Q3 & COURSE: Rate the intellectual challenge of the course & 4.27 & 4.67 & $9.4 \%$ & 0.087 & 4.75 & 4.75 & $0.0 \%$ & $>0.999$ \\
\hline Q4 & $\begin{array}{l}\text { COURSE: Rate quality of assigned HW. Does the } \\
\text { assigned HW help you better understand the course } \\
\text { material? }\end{array}$ & 5.03 & 4.67 & $-7.3 \%$ & 0.201 & 5.35 & 5.19 & $-3.0 \%$ & 0.527 \\
\hline Q5 & $\begin{array}{l}\text { COURSE: Rate how much you have learnt in this } \\
\text { course so far }\end{array}$ & 3.87 & 4.42 & $14.2 \%$ & 0.005 & 4.45 & 4.91 & $10.3 \%$ & 0.100 \\
\hline Q6 & $\begin{array}{l}\text { COURSE: Rate effectiveness of electronic media (e.g., } \\
\text { tablet, projector) to support student learning }\end{array}$ & 4.67 & 4.96 & $6.2 \%$ & 0.374 & 5.3 & 5.31 & $0.2 \%$ & 0.962 \\
\hline Q7 & COURSE: Overall rating for the course & 4.33 & 4.67 & $7.7 \%$ & 0.139 & 5 & 5.22 & $4.4 \%$ & 0.357 \\
\hline Q8 & $\begin{array}{l}\text { INSTRUCTOR: Rate instructor's knowledge of the } \\
\text { course material }\end{array}$ & 5.40 & 5.63 & $4.2 \%$ & 0.164 & 5.95 & 5.81 & $-2.3 \%$ & 0.205 \\
\hline Q9 & $\begin{array}{l}\text { INSTRUCTOR: Rate instructor's presentation and } \\
\text { explanation skills }\end{array}$ & 4.60 & 4.50 & $-2.2 \%$ & 0.707 & 5.3 & 5.22 & $-1.5 \%$ & 0.741 \\
\hline Q10 & $\begin{array}{l}\text { INSTRUCTOR: Rate instructor's enthusiasm about the } \\
\text { class }\end{array}$ & 4.77 & 5.00 & $4.9 \%$ & 0.358 & 5.4 & 5.44 & $0.7 \%$ & 0.884 \\
\hline Q11 & $\begin{array}{l}\text { INSTRUCTOR: Rate instructor's effectiveness in } \\
\text { encouraging interest }\end{array}$ & 4.17 & 4.33 & $4.0 \%$ & 0.590 & 5.05 & 5.03 & $-0.4 \%$ & 0.949 \\
\hline Q12 & $\begin{array}{l}\text { INSTRUCTOR: Rate instructor's preparation for the } \\
\text { class }\end{array}$ & 5.27 & 5.42 & $2.8 \%$ & 0.479 & 5.8 & 5.72 & $-1.4 \%$ & 0.589 \\
\hline Q13 & $\begin{array}{l}\text { INSTRUCTOR: Rate instructor's availability for } \\
\text { assistance }\end{array}$ & 4.90 & 5.00 & $2.0 \%$ & 0.715 & 5.4 & 5.38 & $-0.5 \%$ & 0.900 \\
\hline Q14 & $\begin{array}{l}\text { INSTRUCTOR: Rate class learning environment and } \\
\text { instructor-student Interaction. Does the instructor } \\
\text { encourage this interaction inside and outside the class? }\end{array}$ & 4.40 & 4.13 & $-6.3 \%$ & 0.423 & 5.15 & 5.06 & $-1.7 \%$ & 0.781 \\
\hline Q15 & $\begin{array}{l}\text { INSTRUCTOR: Rate instructor's respect and } \\
\text { professional treatment of the students }\end{array}$ & 5.30 & 5.00 & $-5.7 \%$ & 0.404 & 5.55 & 5.50 & $-0.9 \%$ & 0.849 \\
\hline Q16 & INSTRUCTOR: Overall rating for the instructor & 4.67 & 4.75 & $1.8 \%$ & 0.741 & 5.5 & 5.47 & $-0.6 \%$ & 0.889 \\
\hline
\end{tabular}


Table 2. Instructor 1 - University A - Undergraduate Course of Statics (CVEN 2121) - Larger size classes (Max. Rating: 6)

\begin{tabular}{|c|c|c|c|c|c|}
\hline & & \multicolumn{4}{|c|}{ Statics - Fall 2015} \\
\hline & & $\begin{array}{l}\text { Evaluati } \\
\text { on } 1\end{array}$ & $\begin{array}{l}\text { Evaluation } \\
\quad 2\end{array}$ & \multirow{3}{*}{ 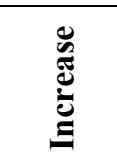 } & \multirow{3}{*}{ 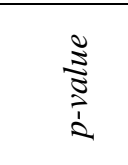 } \\
\hline & No. of Students enrolled & \multicolumn{2}{|c|}{120} & & \\
\hline & Response Rate & $59 \%$ & $53 \%$ & & \\
\hline Q1 & $\begin{array}{l}\text { COURSE: Rate organization of course content (syllabus, } \\
\text { textbook, notes, D2L) }\end{array}$ & 5.00 & 5.23 & $4.7 \%$ & 0.079 \\
\hline Q2 & $\begin{array}{l}\text { COURSE: Rate use of class time. Is the class time } \\
\text { efficiently used to promote student learning? }\end{array}$ & 4.32 & 4.83 & $11.7 \%$ & 0.024 \\
\hline Q3 & COURSE: Rate the intellectual challenge of the course & 4.87 & 4.69 & $-3.8 \%$ & 0.257 \\
\hline Q4 & $\begin{array}{l}\text { COURSE: Rate quality of assigned HW. Does the } \\
\text { assigned HW help you better understand the course } \\
\text { material? }\end{array}$ & 4.30 & 4.75 & $10.6 \%$ & 0.025 \\
\hline Q5 & $\begin{array}{l}\text { COURSE: Rate how much you have learnt in this course } \\
\text { so far }\end{array}$ & 3.86 & 4.70 & $21.9 \%$ & $<0.001$ \\
\hline Q6 & $\begin{array}{l}\text { COURSE: Rate effectiveness of electronic media (e.g., } \\
\text { tablet, projector) to support student learning }\end{array}$ & 4.62 & 5.22 & $13.0 \%$ & 0.003 \\
\hline Q7 & COURSE: Overall rating for the course & 4.00 & 4.81 & $20.3 \%$ & $<0.001$ \\
\hline Q8 & $\begin{array}{l}\text { INSTRUCTOR: Rate instructor's knowledge of the } \\
\text { course material }\end{array}$ & 5.49 & 5.64 & $2.7 \%$ & 0.269 \\
\hline Q9 & $\begin{array}{l}\text { INSTRUCTOR: Rate instructor's presentation and } \\
\text { explanation skills }\end{array}$ & 4.32 & 4.92 & $13.8 \%$ & 0.003 \\
\hline Q10 & $\begin{array}{l}\text { INSTRUCTOR: Rate instructor's enthusiasm about the } \\
\text { class }\end{array}$ & 4.17 & 5.05 & $21.1 \%$ & $<0.001$ \\
\hline Q11 & $\begin{array}{l}\text { INSTRUCTOR: Rate instructor's effectiveness in } \\
\text { encouraging interest }\end{array}$ & 3.49 & 4.58 & $31.1 \%$ & $<0.001$ \\
\hline Q12 & $\begin{array}{l}\text { INSTRUCTOR: Rate instructor's preparation for the } \\
\text { class }\end{array}$ & 5.15 & 5.63 & $9.1 \%$ & 0.001 \\
\hline Q13 & $\begin{array}{l}\text { INSTRUCTOR: Rate instructor's availability for } \\
\text { assistance }\end{array}$ & 4.32 & 4.66 & $7.7 \%$ & 0.133 \\
\hline Q14 & $\begin{array}{l}\text { INSTRUCTOR: Rate class learning environment and } \\
\text { instructor-student Interaction. Does the instructor } \\
\text { encourage this interaction inside and outside the class? }\end{array}$ & 3.45 & 4.48 & $30.0 \%$ & $<0.001$ \\
\hline Q15 & $\begin{array}{l}\text { INSTRUCTOR: Rate instructor's respect and } \\
\text { professional treatment of the students }\end{array}$ & 4.46 & 5.27 & $17.9 \%$ & 0.001 \\
\hline Q16 & INSTRUCTOR: Overall rating for the instructor & 4.10 & 4.91 & $19.7 \%$ & $<0.001$ \\
\hline
\end{tabular}

\begin{tabular}{|c|c|c|c|}
\hline \multicolumn{4}{|c|}{ Statics - Fall 2016} \\
\hline $\begin{array}{c}\text { Evaluati } \\
\text { on } 1\end{array}$ & $\begin{array}{c}\text { Evalua } \\
\text { tion } 2\end{array}$ & \multirow{3}{*}{ 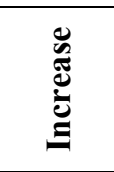 } & \multirow{3}{*}{$\begin{array}{l}\frac{\tilde{2}}{0} \\
\frac{1}{1} \\
\stackrel{1}{2}\end{array}$} \\
\hline \multicolumn{2}{|c|}{106} & & \\
\hline $40 \%$ & $30 \%$ & & \\
\hline 5.48 & 5.25 & $-4.1 \%$ & 0.264 \\
\hline 5.29 & 5.13 & $-3.0 \%$ & 0.506 \\
\hline 4.93 & 4.78 & $-3.0 \%$ & 0.427 \\
\hline 5.38 & 4.72 & $-12.3 \%$ & 0.002 \\
\hline 4.69 & 4.69 & $-0.1 \%$ & 0.990 \\
\hline 5.07 & 5.31 & $4.8 \%$ & 0.370 \\
\hline 5.07 & 4.88 & $-3.9 \%$ & 0.402 \\
\hline 5.83 & 5.69 & $-2.5 \%$ & 0.214 \\
\hline 5.17 & 4.91 & $-5.0 \%$ & 0.316 \\
\hline 5.31 & 5.22 & $-1.7 \%$ & 0.734 \\
\hline 5.02 & 4.72 & $-6.1 \%$ & 0.308 \\
\hline 5.64 & 5.66 & $0.2 \%$ & 0.924 \\
\hline 5.12 & 4.72 & $-7.8 \%$ & 0.123 \\
\hline 4.93 & 4.75 & $-3.6 \%$ & 0.511 \\
\hline 5.64 & 5.22 & $-7.5 \%$ & 0.069 \\
\hline 5.45 & 5.16 & $-5.4 \%$ & 0.161 \\
\hline
\end{tabular}


Table 3. Instructor 1 - University A - Graduate Course of Structural Dynamics (CVEN 5111) (Max. Rating: 6)

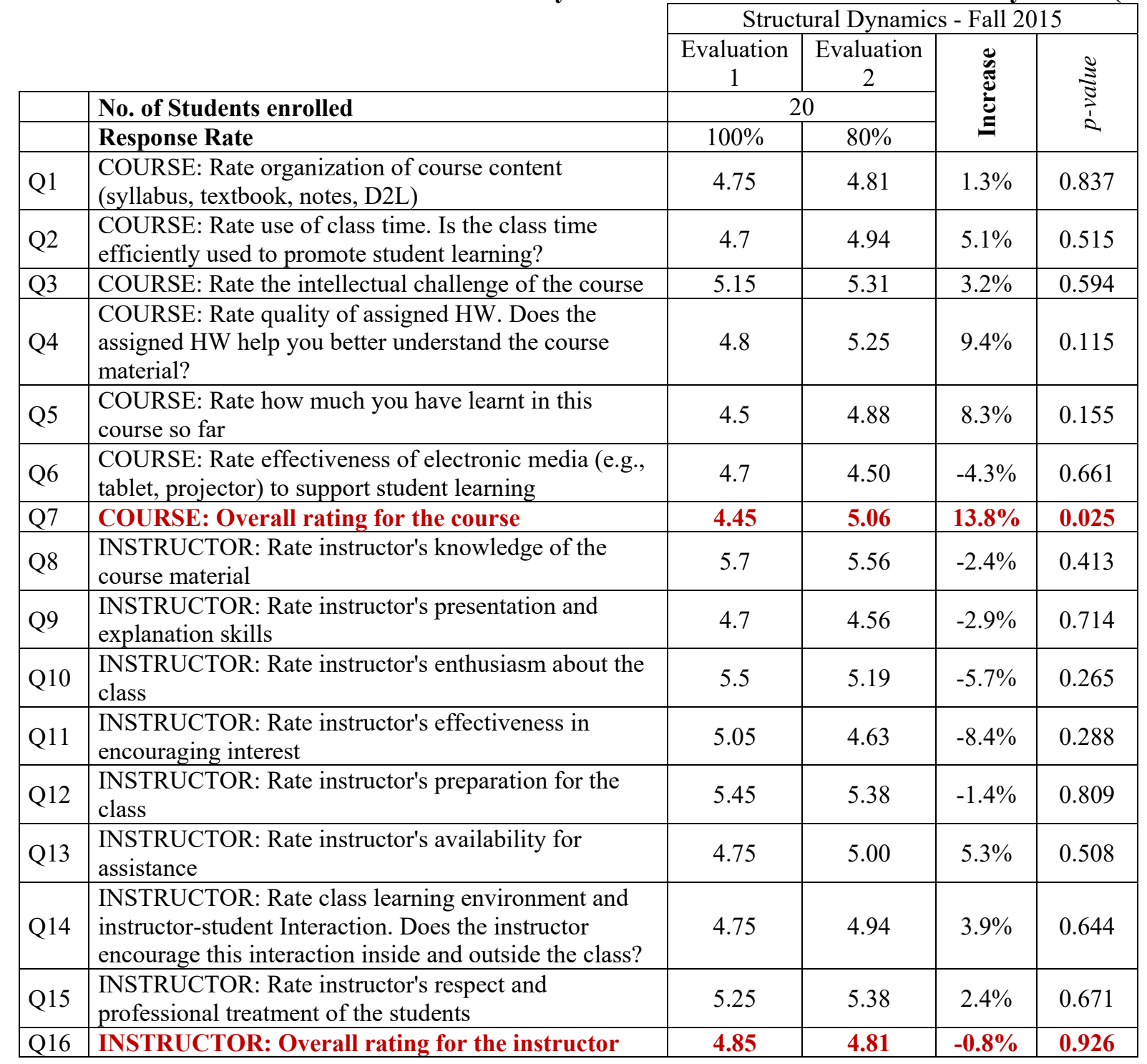

\begin{tabular}{|c|c|c|c|}
\hline \multicolumn{4}{|c|}{ Structural Dynamics - Fall 2016} \\
\hline $\begin{array}{c}\text { Evaluatio } \\
\text { n } 1\end{array}$ & $\begin{array}{c}\text { Evaluation } \\
2\end{array}$ & \multirow{3}{*}{ 总 } & \multirow{3}{*}{$\begin{array}{l}0 \\
\frac{1}{0} \\
0 \\
1 \\
2\end{array}$} \\
\hline \multicolumn{2}{|c|}{19} & & \\
\hline $68 \%$ & $53 \%$ & & \\
\hline 4.77 & 5.60 & $17.4 \%$ & 0.038 \\
\hline 4.77 & 5.20 & $9.0 \%$ & 0.296 \\
\hline 5.31 & 5.50 & $3.6 \%$ & 0.652 \\
\hline 4.77 & 5.30 & $11.1 \%$ & 0.167 \\
\hline 4.77 & 5.20 & $9.0 \%$ & 0.243 \\
\hline 4.69 & 5.20 & $10.8 \%$ & 0.256 \\
\hline 4.31 & 5.10 & $18.4 \%$ & 0.005 \\
\hline 5.62 & 5.70 & $1.5 \%$ & 0.688 \\
\hline 4.62 & 5.40 & $17.0 \%$ & 0.050 \\
\hline 5.62 & 5.70 & $1.5 \%$ & 0.745 \\
\hline 5.08 & 5.10 & $0.5 \%$ & 0.948 \\
\hline 5.38 & 5.60 & $4.0 \%$ & 0.460 \\
\hline 5.23 & 5.50 & $5.1 \%$ & 0.381 \\
\hline 5.38 & 5.60 & $4.0 \%$ & 0.491 \\
\hline 5.31 & 5.30 & $-0.1 \%$ & 0.986 \\
\hline 4.92 & 5.40 & $9.7 \%$ & 0.134 \\
\hline
\end{tabular}


Table 4. Instructor 1 - University B - Undergraduate Course of Computer Applications in Engineering and Construction (CVEN 302) (Max. Rating: 5)

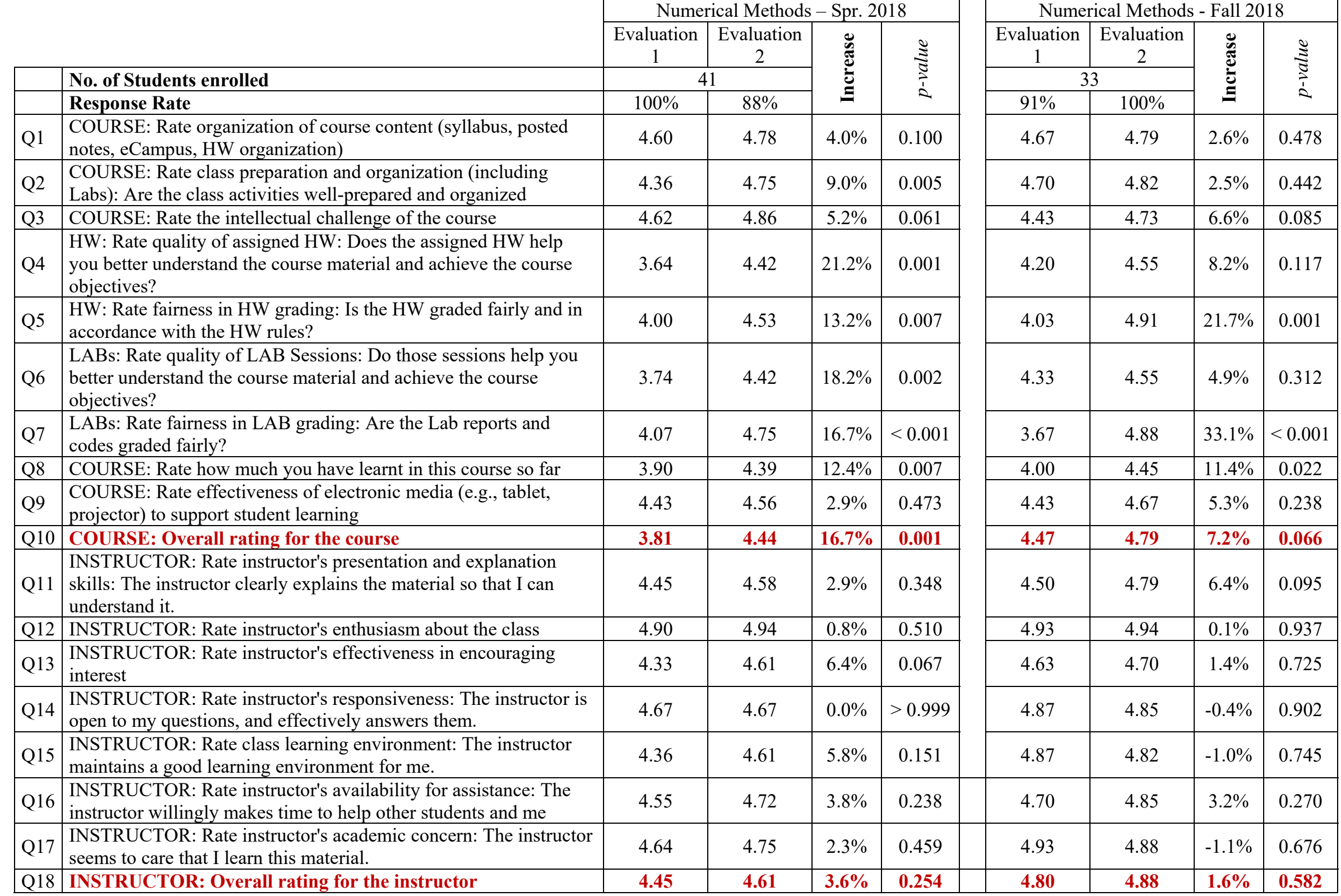


Table 5. Instructor 1 - University B - Undergraduate Course of Structural Concrete Design (CVEN 444) (Max. Rating: 5)

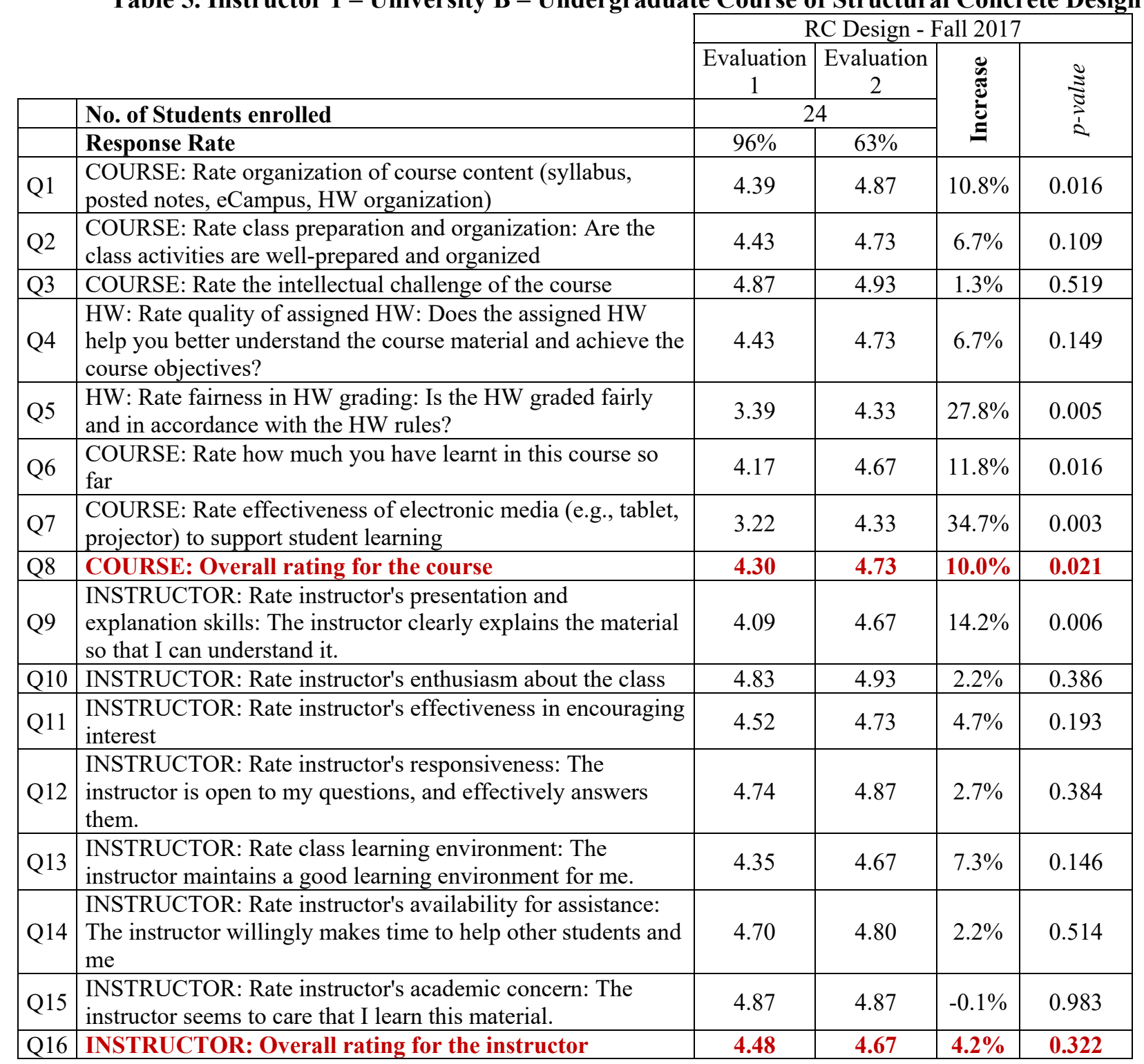

\begin{tabular}{|c|c|c|c|}
\hline \multicolumn{4}{|c|}{ RC Design - Spring 2019} \\
\hline $\begin{array}{c}\text { Evaluation } \\
1\end{array}$ & $\begin{array}{c}\text { Evaluation } \\
2\end{array}$ & \multirow{3}{*}{ 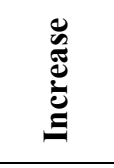 } & \multirow{3}{*}{ 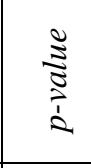 } \\
\hline \multicolumn{2}{|c|}{57} & & \\
\hline $77 \%$ & $77 \%$ & & \\
\hline 4.50 & 4.84 & $7.6 \%$ & 0.018 \\
\hline 4.18 & 4.66 & $11.4 \%$ & 0.002 \\
\hline 4.82 & 4.70 & $-2.4 \%$ & 0.269 \\
\hline 3.98 & 4.41 & $10.9 \%$ & 0.016 \\
\hline 4.07 & 3.93 & $-3.4 \%$ & 0.437 \\
\hline 3.55 & 4.23 & $19.2 \%$ & 0.001 \\
\hline 4.20 & 4.45 & $5.9 \%$ & 0.172 \\
\hline 3.86 & 4.43 & $14.7 \%$ & 0.001 \\
\hline 3.86 & 4.52 & $17.1 \%$ & 0.001 \\
\hline 4.86 & 4.95 & $1.9 \%$ & 0.194 \\
\hline 4.23 & 4.57 & $8.1 \%$ & 0.044 \\
\hline 4.41 & 4.77 & $8.2 \%$ & 0.036 \\
\hline 4.14 & 4.66 & $12.6 \%$ & 0.006 \\
\hline 4.32 & 4.68 & $8.4 \%$ & 0.037 \\
\hline 4.68 & 4.95 & $5.8 \%$ & 0.013 \\
\hline 4.07 & 4.64 & $14.0 \%$ & 0.001 \\
\hline
\end{tabular}


Table 6. Instructor 1 - University B - Graduate Course of Advanced Mechanics of Materials (CVEN 633) (Max. Rating: 5)

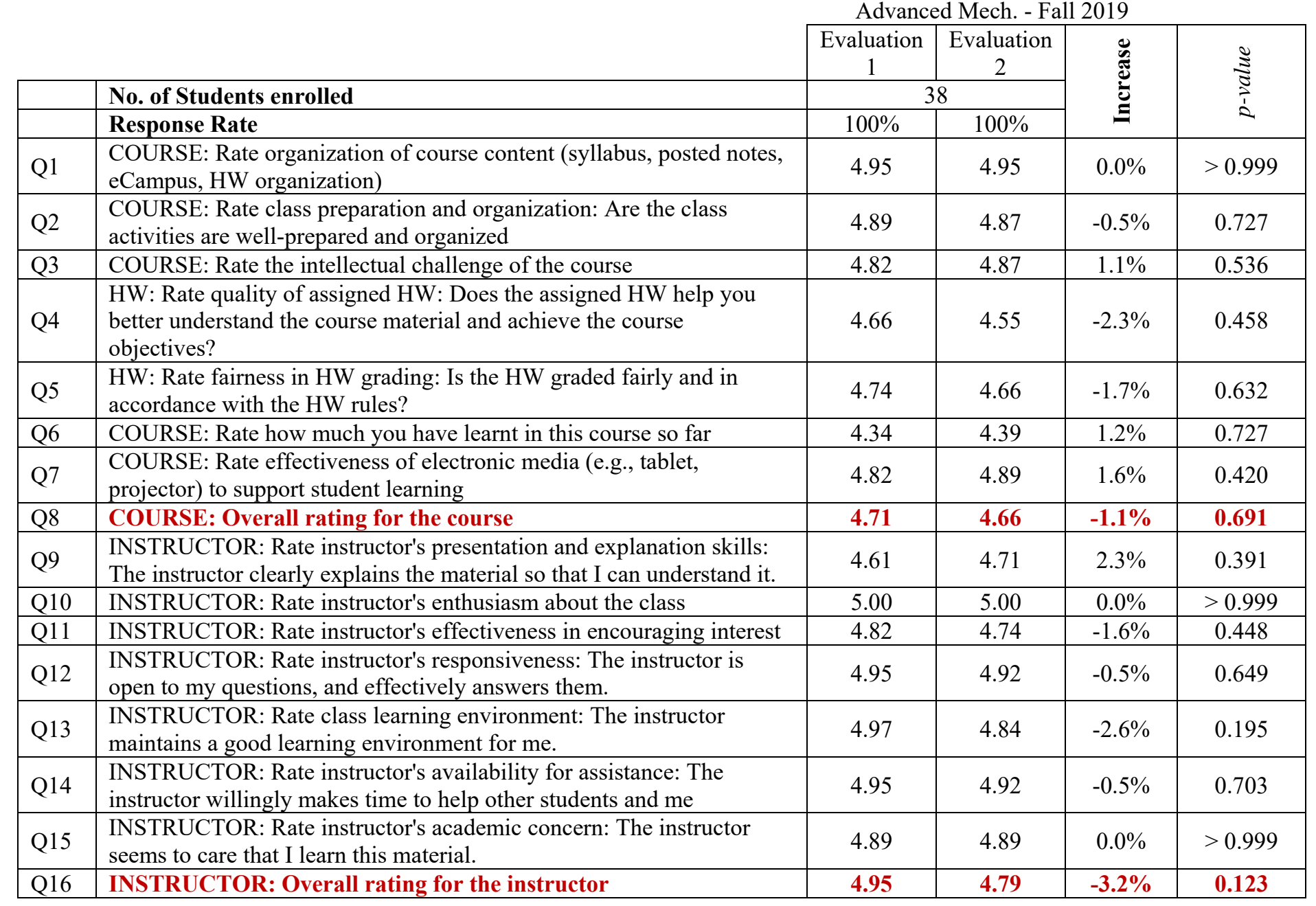


Table 7. Instructor 2 - University B - Undergraduate Course of Engineering Mechanics: Dynamics (CVEN 363) (Max. Rating: 5)

\begin{tabular}{|c|c|c|c|c|c|}
\hline & \multicolumn{4}{|c|}{ Eng. Dynamics - Spring 2018} \\
\hline & & $\begin{array}{c}\text { Evaluation } \\
1\end{array}$ & Final & \multirow{3}{*}{ 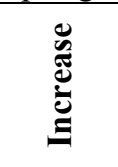 } & \multirow{3}{*}{ 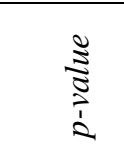 } \\
\hline & No. of Students enrolled & \multicolumn{2}{|c|}{$\begin{array}{r}1 \\
69 \\
\end{array}$} & & \\
\hline & Response Rate & $87 \%$ & $91 \%$ & & \\
\hline Q1 & $\begin{array}{l}\text { Class Preparation: The class activities } \\
\text { are well-prepared and organized }\end{array}$ & 4.2 & 4.66 & $11.0 \%$ & $<0.001$ \\
\hline Q2 & $\begin{array}{l}\text { Assignments: The examinations, } \\
\text { assignments, projects, etc. aid me in } \\
\text { achieving the class objectives. }\end{array}$ & 3.93 & 4.56 & $16.0 \%$ & $<0.001$ \\
\hline Q3 & $\begin{array}{l}\text { Communications: The instructor clearly } \\
\text { explains material so that I can } \\
\text { understand it. }\end{array}$ & 3.88 & 4.48 & $15.5 \%$ & $<0.001$ \\
\hline Q4 & $\begin{array}{l}\text { Responsiveness: The instructor is open } \\
\text { to my questions, and effectively } \\
\text { answers them. }\end{array}$ & 4.02 & 4.52 & $12.4 \%$ & $<0.001$ \\
\hline Q5 & $\begin{array}{l}\text { Academic concern: The instructor } \\
\text { seems to care that I learn this material. }\end{array}$ & 4.05 & 4.52 & $11.6 \%$ & $<0.001$ \\
\hline Q6 & $\begin{array}{l}\text { Availability: The instructor willingly } \\
\text { makes time to help other students and } \\
\text { me }\end{array}$ & 3.88 & 4.45 & $14.7 \%$ & $<0.001$ \\
\hline Q7 & $\begin{array}{l}\text { Fairness in Grading: The instructor is } \\
\text { fair and consistent in evaluating my } \\
\text { performance in the course. }\end{array}$ & 3.87 & 4.56 & $17.8 \%$ & $<0.001$ \\
\hline Q8 & $\begin{array}{l}\text { Environment: The instructor maintains } \\
\text { a good learning environment for me. }\end{array}$ & 4.05 & 4.48 & $10.6 \%$ & $<0.001$ \\
\hline Q9 & Overall Average & 3.99 & 4.53 & $13.6 \%$ & \\
\hline
\end{tabular}

\begin{tabular}{|c|c|c|c|}
\hline \multicolumn{4}{|c|}{ Eng. Dynamics - Spring 2019} \\
\hline $\begin{array}{c}\text { Evaluation } \\
1\end{array}$ & $\begin{array}{c}\text { Evaluation } \\
2\end{array}$ & \multirow{3}{*}{ 总 } & \multirow{3}{*}{ 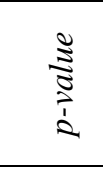 } \\
\hline \multicolumn{2}{|c|}{76} & & \\
\hline $87 \%$ & $91 \%$ & & \\
\hline 4.94 & 4.83 & $-2.2 \%$ & 0.072 \\
\hline 4.81 & 4.75 & $-1.2 \%$ & 0.421 \\
\hline 4.73 & 4.7 & $-0.6 \%$ & 0.772 \\
\hline 4.95 & 4.9 & $-1.0 \%$ & 0.301 \\
\hline 4.92 & 4.92 & $0.0 \%$ & 0.915 \\
\hline 4.89 & 4.87 & $-0.4 \%$ & 0.807 \\
\hline 4.81 & 4.77 & $-0.8 \%$ & 0.664 \\
\hline 4.9 & 4.9 & $0.0 \%$ & 0.953 \\
\hline 4.87 & 4.83 & $-0.8 \%$ & \\
\hline
\end{tabular}


Table 8. Instructor 2 - University B - Undergraduate Course of Engineering Mechanics: Dynamics (CVEN 363) (Max. Rating: 5) and Graduate Course of Engineering Risk Analysis (CVEN 699) (Max. Rating: 5)

\begin{tabular}{|c|c|c|c|c|c|}
\hline & \multicolumn{4}{|c|}{ Steel Design - Fall 2017} \\
\hline & & $\begin{array}{c}\text { Evaluation } \\
1\end{array}$ & Final & \multirow{3}{*}{ 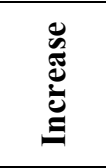 } & \multirow{3}{*}{$\frac{\mathfrak{2}}{\mathfrak{D}}$} \\
\hline & No. of Students enrolled & \multicolumn{2}{|c|}{24} & & \\
\hline & Response Rate & $58 \%$ & $83 \%$ & & \\
\hline Q1 & $\begin{array}{l}\text { Class Preparation: The class activities are well- } \\
\text { prepared and organized }\end{array}$ & 4.14 & 4.65 & $12.3 \%$ & 0.023 \\
\hline Q2 & $\begin{array}{l}\text { Assignments: The examinations, assignments, } \\
\text { projects, etc. aid me in achieving the class } \\
\text { objectives. }\end{array}$ & 4.14 & 4.75 & $14.7 \%$ & 0.007 \\
\hline Q3 & $\begin{array}{l}\text { Communications: The instructor clearly explains } \\
\text { material so that I can understand it. }\end{array}$ & 4 & 4.5 & $12.5 \%$ & 0.019 \\
\hline Q4 & $\begin{array}{l}\text { Responsiveness: The instructor is open to my } \\
\text { questions, and effectively answers them. }\end{array}$ & 4.5 & 4.65 & $3.3 \%$ & 0.403 \\
\hline Q5 & $\begin{array}{l}\text { Academic concern: The instructor seems to care } \\
\text { that I learn this material. }\end{array}$ & 4.36 & 4.65 & $6.7 \%$ & 0.100 \\
\hline Q6 & $\begin{array}{l}\text { Availability: The instructor willingly makes time } \\
\text { to help other students and me }\end{array}$ & 4.36 & 4.55 & $4.4 \%$ & 0.280 \\
\hline Q7 & $\begin{array}{l}\text { Fairness in Grading: The instructor is fair and } \\
\text { consistent in evaluating my performance in the } \\
\text { course. }\end{array}$ & 4.29 & 4.65 & $8.4 \%$ & 0.037 \\
\hline Q8 & $\begin{array}{l}\text { Environment: The instructor maintains a good } \\
\text { learning environment for me. }\end{array}$ & 4.29 & 4.4 & $2.6 \%$ & 0.613 \\
\hline Q9 & Overall Average & 4.26 & 4.60 & $8.0 \%$ & \\
\hline
\end{tabular}

\begin{tabular}{|c|c|c|c|}
\hline \multicolumn{4}{|c|}{ Structural Risk - Fall 2018} \\
\hline $\begin{array}{c}\text { Evaluation } \\
1\end{array}$ & $\begin{array}{c}\text { Evaluation } \\
2\end{array}$ & \multirow{3}{*}{ 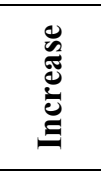 } & \multirow{3}{*}{ 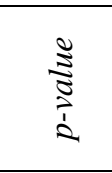 } \\
\hline \multicolumn{2}{|c|}{26} & & \\
\hline $77 \%$ & $77 \%$ & & \\
\hline 4.9 & 4.8 & $-2.0 \%$ & 0.389 \\
\hline 4.8 & 4.35 & $-9.4 \%$ & 0.047 \\
\hline 4.55 & 4.2 & $-7.7 \%$ & 0.139 \\
\hline 4.95 & 4.85 & $-2.0 \%$ & 0.305 \\
\hline 4.85 & 4.95 & $2.1 \%$ & 0.305 \\
\hline 4.95 & 5 & $1.0 \%$ & 0.330 \\
\hline 4.95 & 4.95 & $0.0 \%$ & $>0.999$ \\
\hline 4.9 & 4.8 & $-2.0 \%$ & 0.467 \\
\hline 4.86 & 4.74 & $-2.4 \%$ & \\
\hline
\end{tabular}




\section{Summary and Conclusions}

This paper presents a student-centered assessment model that provides timely actionable feedback allowing optimization of course instruction during the semester with the goal of maximizing student learning and overall student satisfaction. The proposed model incorporates a structured approach that includes: (i) questions requiring numerical scores and open-ended questions to solicit student feedback, (ii) mechanisms to assess, address and implement that feedback, and (iii) methods to validate the success of the implemented improvements. The proposed model has been implemented in two universities and has been utilized by two faculty. Implementation of this assessment model resulted in an increase of the students' satisfaction within the semester (in terms of mean student ratings) and has led to long-term improvements in the instruction and overall organization of those courses.

A major advantage of the proposed assessment model is that it is easy to implement and requires minimal time from the instructor and the students, as it is applied at discrete time over the semester.

The proposed assessment model has been found to clearly improve the quality of course instruction and learning environment and results in higher student satisfaction. The improvements are larger (and statistically significant with a confidence level of 95\%) when the reference student ratings (i.e. the rating of the first course evaluation $-2^{\text {nd }}$ Survey of the model) are below $80-85 \%$, mainly because there is a larger room for improvement. On the contrary, for reference student ratings exceeding $90-95 \%$, the proposed assessment model is not always capable of guaranteeing increases in the overall student satisfaction (mean student ratings), because minor changes in the course design and delivery can have large consequences for the students. The achieved improvements were found to be larger for large size classes and for courses taught for the first time (or only 1-2 times) by an instructor. The overall student satisfaction about the course and the instructor was found to be correlated with the perceived student learning (i.e. the confidence that the students have in their understanding of the course material).

The authors' strategy of setting target response rates, in the range of $90 \%$ or $95 \%$, and associating them with a small bonus to the upcoming midterm exams or the final exam, was found to achieve its goal, resulting in very high student participation in the course evaluation surveys, which are essential for the success of the assessment model.

The proposed assessment model, despite sharing some similar objectives with the Plus/Delta model [13], is different in that it is structured to not only identify areas of concern, but also to propose and implement improvement strategies, and moreover validate the success of the implemented strategies. Also, its surveys include a much more extensive list of questions to thoroughly assess various aspects of the course structure and delivery. Furthermore, unlike the Plus/Delta approach, this strategy does not require the students to explicitly state their contribution to their learning. Yet, such open ended questions could be added to the surveys of the proposed model in order to further help students realize their responsibility to their own learning. 


\section{Acknowledgements}

The authors would like to acknowledge the feedback provided by Ms. Georgia Angeliki Koliou on the execution of the data analysis.

\section{References}

[1] S. Bloxham and P. Boyd, Developing Effective Assessment In Higher Education: A Practical Guide: A Practical Guide. McGraw-Hill Education (UK), 2007.

[2] E. Blair and K. Valdez Noel, "Improving higher education practice through student evaluation systems: is the student voice being heard?," Assessment \& Evaluation in Higher Education, vol. 39, no. 7, pp. 879-894, 2014.

[3] L. Grebennikov and M. Shah, "Student voice: using qualitative feedback from students to enhance their university experience," Teaching in Higher Education, vol. 18, no. 6, pp. 606-618, 2013.

[4] S. Watson, "Closing the feedback loop: Ensuring effective action from student feedback," Tertiary education and management, vol. 9, no. 2, pp. 145-157, 2003.

[5] A. McKenna, F. McMartin, Y. Terada, V. Sirivedhin, and A. Agogino, "A Framework for Interpreting Students' Perceptions of an Integrated Curriculum," age, vol. 6, p. 1, 2001.

[6] F. J. E. and O. M. W., "Integrated Engineering Curricula," Journal of Engineering Education, vol. 94, no. 1, pp. 147-164, 2005.

[7] H. M. Matusovich, R. A. Streveler, and R. L. Miller, "Why do students choose engineering? A qualitative, longitudinal investigation of students' motivational values," Journal of Engineering Education, vol. 99, no. 4, pp. 289-303, 2010.

[8] A. Irons, Enhancing learning through formative assessment and feedback. Routledge, 2007.

[9] V. J. Shute, "Focus on formative feedback," Review of educational research, vol. 78, no. 1, pp. 153-189, 2008.

[10] B. G. Davis, Tools for teaching. John Wiley \& Sons, 2009.

[11] S. L. Benton and W. E. Cashin, "Idea paper\# 50 student ratings of teaching: A summary of research and literature," 2012.

[12] A. C. Estes, R. W. Welch, and S. J. Ressler, "The ExCEEd teaching model," Journal of Professional Issues in Engineering Education and Practice, vol. 131, no. 4, pp. 218-222, 2005.

[13] L. Helminski and S. Koberna, "Total Quality in Instruction: A Systems Approach [Academic Initiatives in Total Quality for Higher Education. Edited by Roberts HV]," ed: Milwaukee, WI: ASQC Quality Press, 1995. 